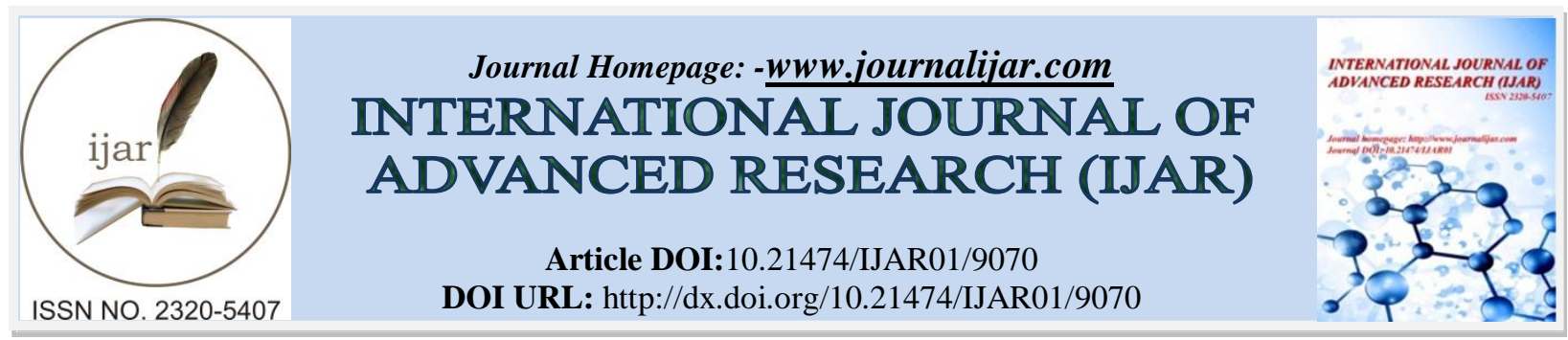

RESEARCH ARTICLE

\title{
FORMULATION AND EVALUATION OF FLOATING MICROSPHERES OF FAMOTIDINE HYDROCHLORIDE.
}

\author{
Someshwar Tiwari ${ }^{1}$, S. Satyanandam ${ }^{1}$, M.A Saleem ${ }^{1}$ and Sushil Kumar sah ${ }^{2}$. \\ 1. Luqman college of pharmacy, Gulbarga, Karnataka. \\ 2. Birat Medical College, Biratnagar, Nepal.
}

\section{Manuscript Info}

Manuscript History

Received: 15 March 2019

Final Accepted: 17 April 2019

Published: May 2019

Key words:-

Famotidine $\mathrm{HCl}$, ethylcellulose Sodium alginate, floating microspheres.

\section{Abstract}

Controlled release gastric floating drug delivery system has a bulk density less than gastric fluids, so it remain buoyant in the stomach without affecting the gastric emptying rate for prolonged period of time. There by releasing the drug for prolonged period of time constantly to the upper part of the GIT and improves the bioavailability of drug with narrow absorption window. Famotidine is a histaminic drug that has been widely used in treating gastric and duodenal ulceration and also in zollinger elison syndrome and reflux oesophagitis. It works by reducing swelling and constricting blood vessels in the GIT passage, allowing you to get relief from gastritis easily.

Floating microspheres are gastro-retentive drug delivery system. These microspheres are free flowing powders, gastric contents for prolonged time. Hence faster dissolution of dosage form results in faster absorption and onset of action. Floating microspheres are absorbed from mouth, pharynx and esophagus as the saliva passes down the stomach. In such cases the bioavailability is greater than those observed for conventional dosage form.

Different polymers such as ethyl cellulose, sodium alginate were optimized with different concentration and varying the ratios in order to get the sustained release profile over a period of $24 \mathrm{hrs}$. All the formulations were evaluated for in-vitro buoyancy, entrapment efficiency and in-vitro drug release profile. The results revealed that the present buoyancy is more than $70 \%$ after $24 \mathrm{hrs}$. The mean particle size of microspheres was in the range of $102.33-420.53 \mu \mathrm{m}$. In-vitro release of floating microspheres of Famotidine HCL was found to be in following order,H1>HE1 $>\mathrm{H} 2>\mathrm{HE} 4>\mathrm{E} 1>\mathrm{HE} 2>\mathrm{H} 3>\mathrm{HE} 3>\mathrm{HE} 5>\mathrm{E} 2>\mathrm{E} 3$. H1 was found to be the best formulation among all other formulation prepared as it release Famotidine HCL $98.84 \%$ in a sustained manner with constant fashion over extended period of time (after $24 \mathrm{hr}$ ). 


\section{Introduction:-}

The goal of any drug delivery system is to provide a therapeutic amount of drug to the proper site in the body to achieve promptly and then maintain the desired drug concentration. The most convenient and commonly employed route of drug delivery has historically been by oral ingestion ${ }^{1}$.

The oral route of drug administration is the most important method of administering drugs for systemic effects. The parentral route is not routinely used; the topical route of administration has only recently been employed to deliver drugs to the body for systemic effects. It is probable that at least $90 \%$ of all drugs used to produce systemic effects are administered by the oral route. When a new drug is discovered, one of the first questions a pharmaceutical company asks is whether or not the drug can be effectively administered for its intended effect by the oral route. If it cannot, the drug is primarily relegated to administration in a hospital setting or physician's office, of drugs that are administered orally; solid oral dosage forms represent the preferred class of product ${ }^{2}$.

Recent scientific and patent literature shows increased interest in academics and industrial research groups regarding the novel dosage forms that can be retained in the stomach for a prolonged and predictable period of time. One of the most feasible approaches for achieving a prolonged and predictable drug delivery profile in the GI tract is to control the gastric residence time (GRT), using gastroretentive drug delivery system (GRDDS) that will provide us with new and important therapeutic options ${ }^{1}$.Gastroretentive system can remain in the gastric region for several hours and hence significantly prolong the gastric residence time of drugs. Prolonged gastric retention improves bioavailability, reduces drug waste, and improves solubility of drugs that are less soluble in a high pH environment. It has applications also for local drug delivery to the stomach and proximal small intestines. Gastro retention helps to provide better availability of new products with new therapeutic possibilities and substantial benefits for patients ${ }^{\mathbf{1 0}}$. Drug dissolution and release from the capsule retained in stomach fluids occur at the stomach, under fairly controlled condition. The retentive characteristics of the dosage form in gastric content are most significant for drugs which are insoluble in intestinal fluid, that acts locally and that exhibits site specific absorption.

\section{Methods:-}

Preformulation study relates to pharmaceutical and analytical investigation carried out for proceeding and supporting formulation development efforts of the dosage form of the drug substance. Famotidine was procured from apex pharmaceutical, Nepal. The other excipients were gift sample of Quest pharmaceutical, Nepal.

\section{preparation of floating microspheres}

The microspheres were prepared by Solvent evaporation method. The $500 \mathrm{mg}$ of drug was dispersed uniformly in aqueous mucilage of sodium alginate, to this dispersion desired polymer was mixed in suitable proportion, than 100 mg of gas forming agent such as sodium bicarbonate $\left(\mathrm{NaHCO}_{3}\right)$ was separately added to the solution. The resulting solution was dropped through a $26 \mathrm{G}$ syringe needle in to $5 \%(\mathrm{w} / \mathrm{v})$ sodium bicarbonate $\left(\mathrm{NaHCO}_{3}\right)$ which is prepared in water containing $10 \%(\mathrm{v} / \mathrm{v})$ acetic acid. The solution containing suspended microspheres was kept for $1.5 \mathrm{hrs}$, to improve the mechanical strength of the microspheres and allowed to complete the reaction to produce gas. The fully formed microspheres were collected, washed with distilled water and subsequently air dried.

\section{Results and Discussion:-}

The prepared microspheres were characterized by FTIR spectroscopy to find out any chemical interaction between Famotidine $\mathrm{HCl}$ and polymers used. The FTIR spectra of Famotidine HCl, polymers and the physical mixture of drug with polymer is shown in the figure-21-24. Our experimental results were assesed on the basis of physical data obtained for drug and polymers as well as by hysical mixture. 


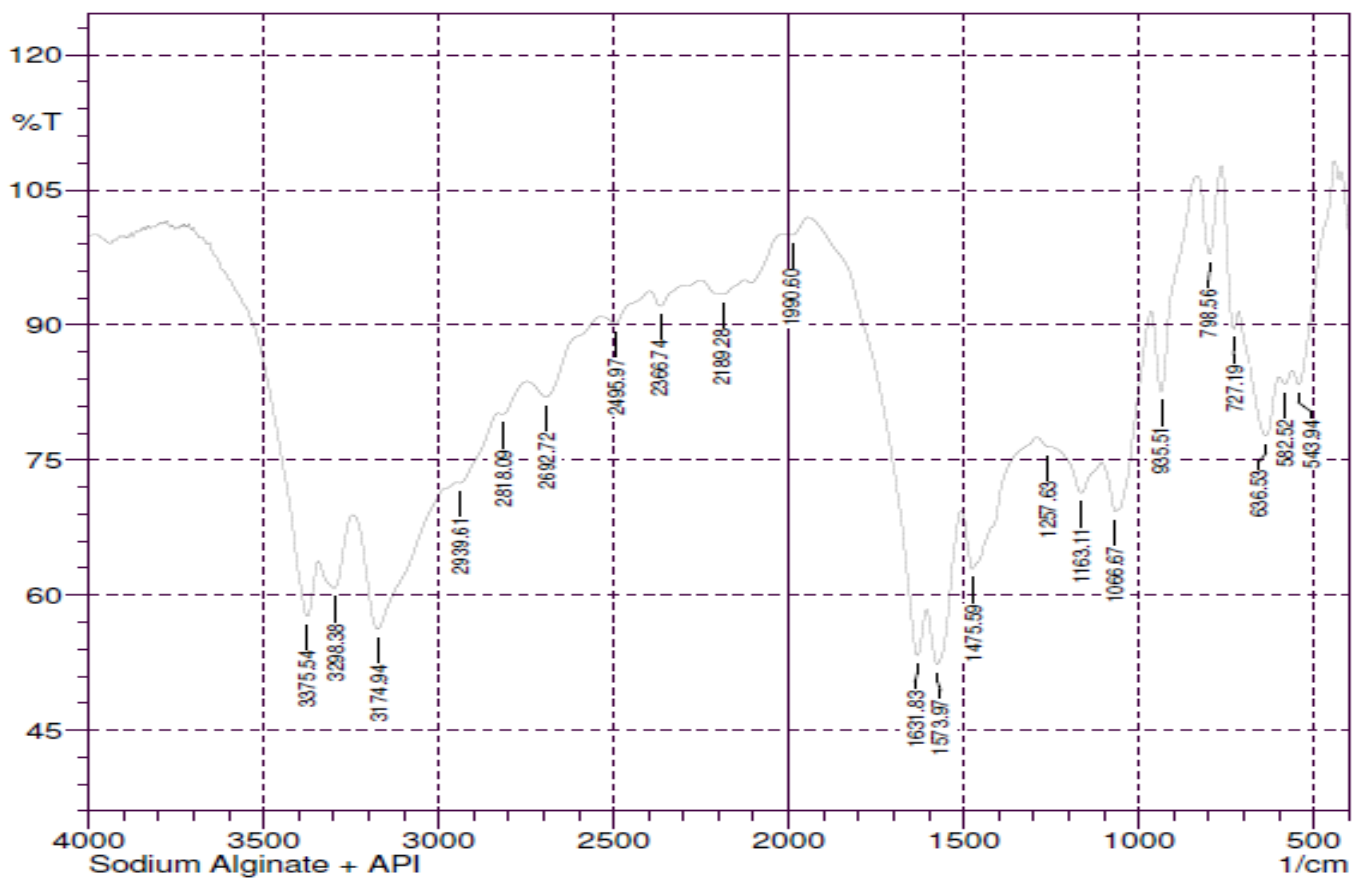

Fig 1:-FTIR spectra of Famotidine $\mathrm{HCl}$ with sodium alginate

Table 1:-Evaluation of prepared microspheres.

\begin{tabular}{|c|c|c|c|c|c|}
\hline $\begin{array}{c}\text { Formulation } \\
\text { Code }\end{array}$ & $\begin{array}{c}\text { Angle of } \\
\text { repose }(\boldsymbol{\theta}) \\
\mathbf{\pm S D}\end{array}$ & $\begin{array}{c}\text { Bulk } \\
\text { Density } \\
(\mathbf{g} / \mathbf{m l}) \pm \mathbf{S D}\end{array}$ & $\begin{array}{c}\text { Tapped } \\
\text { Density } \\
(\mathbf{g} / \mathbf{m l}) \pm \mathbf{S D}\end{array}$ & $\begin{array}{c}\text { Carr's } \\
\text { Index } \\
(\boldsymbol{\%}) \pm \mathbf{S D}\end{array}$ & $\begin{array}{c}\text { Hausner's } \\
\text { Ratio } \pm \text { SD }\end{array}$ \\
\hline H-1 & $22.83 \pm 1.24$ & $0.460 \pm 0.05$ & $0.513 \pm 0.07$ & $10.33 \pm 0.91$ & $1.11 \pm 0.12$ \\
\hline H-2 & $25.21 \pm 1.42$ & $0.612 \pm 1.01$ & $0.732 \pm 0.69$ & $16.39 \pm 0.25$ & $1.19 \pm 0.06$ \\
\hline H-3 & $27.45 \pm 0.99$ & $0.782 \pm 0.07$ & $0.672 \pm 0.12$ & $0.701 \pm 0.45$ & $1.11 \pm 0.15$ \\
\hline E-1 & $23.20 \pm 0.59$ & $0.672 \pm 0.09$ & $0.709 \pm 0.04$ & $5.21 \pm 0.10$ & $1.05 \pm 0.04$ \\
\hline E-2 & $24.64 \pm 0.97$ & $0.701 \pm 0.18$ & $0.785 \pm 0.12$ & $10.70 \pm 0.07$ & $1.11 \pm 0.08$ \\
\hline E-3 & $26.36 \pm 0.81$ & $0.781 \pm 0.12$ & $0.856 \pm 0.62$ & $8.76 \pm 0.69$ & $1.09 \pm 0.04$ \\
\hline HE-1 & $22.96 \pm 1.19$ & $0.812 \pm 1.09$ & $0.892 \pm 0.16$ & $8.96 \pm 0.59$ & $1.09 \pm 0.08$ \\
\hline HE-2 & $26.22 \pm 1.37$ & $0.768 \pm 0.04$ & $0.815 \pm 0.52$ & $5.76 \pm 0.21$ & $1.06 \pm 0.05$ \\
\hline HE-3 & $27.89 \pm 1.23$ & $0.621 \pm 0.12$ & $0.711 \pm 0.35$ & $12.65 \pm 0.29$ & $1.14 \pm 0.04$ \\
\hline HE-4 & $22.84 \pm 1.62$ & $0.725 \pm 0.31$ & $0.796 \pm 0.52$ & $8.91 \pm 0.26$ & $1.09 \pm 0.09$ \\
\hline HE-5 & $27.72 \pm 1.91$ & $0.682 \pm 0.49$ & $0.741 \pm 0.74$ & $7.96 \pm 0.19$ & $1.08 \pm 1.02$ \\
\hline
\end{tabular}

All value represented as mean \pm standard deviation $(n=3)$

The mean particle size of the microspheres formulation H1 to HE5 containing HPMC K4M, ethyl cellulose and sodium alginate as in the range of $445.7 \pm 1.34$ to $726.24 \pm 0.95 \mu \mathrm{m}$ respectively (as shown in table 10 ). The effect of polymer concentration on the particle size of microspheres was determined. The mean particle size of the microspheres was found to increase with increasing polymer concentration (as shown in table 10) and the viscosity of the medium increases with increase in concentration of polymer. This results in the formation of larger particles. The bulk density, tapped density, hausners ratio of formulations H1 to HE5 was found in the range of $0.460 \pm 0.05$ to $0.812 \pm 1.09 \mathrm{gm} / \mathrm{cm}^{3}$ (as shown in table 9).

The carr's index of formulations H1 to HE5 was found to be in the range of $22.83 \pm 1.24$ to $27.89 \pm 1.23$. The angle of repose of formulations $\mathrm{H} 1$ to HE5 containing different grades of HPMC K4M, ethyl-cellulose and sodium alginate was in the range of $26.02 \pm 1.71$ to $32.49 \pm 3.39$ respectively (as shown in table 9) The values of carr's index and angle of repose indicate excellent flow properties. 
Tabel 2:-Evaluation of size distribution and size analysis

\begin{tabular}{|c|c|c|c|c|}
\hline \multirow{2}{*}{ Formulation code } & \multicolumn{4}{|c|}{ Particle size } \\
\cline { 2 - 4 } & Trial-1 & Trial-2 & Trial-3 & Mean \pm SD \\
\hline H-1 & 444.6 & 447.2 & 445.3 & $445.7 \pm 1.34$ \\
\hline H-2 & 482.7 & 486.2 & 481.2 & $483.3 \pm 2.56$ \\
\hline H-3 & 516.3 & 519.1 & 515.4 & $516.9 \pm 0.86$ \\
\hline E-1 & 621.6 & 625.2 & 623.1 & $623.3 \pm 0.87$ \\
\hline E-2 & 655.2 & 662.3 & 660.8 & $659.4 \pm 0.80$ \\
\hline E-3 & 684.3 & 685.2 & 686.3 & $685.2 \pm 0.74$ \\
\hline HE-1 & 626.2 & 630.1 & 625.7 & $627.3 \pm 0.70$ \\
\hline HE-3 & 672.5 & 675.2 & 670.1 & $672.6 \pm 0.66$ \\
\hline HE-4 & 723.2 & 725.6 & 722.3 & $723.7 \pm 0.63$ \\
\hline HE-5 & 685.1 & 687.3 & 688.2 & $686.8 \pm 1.59$ \\
\hline & 725.2 & 727.1 & 726.2 & $726.1 \pm 0.95$ \\
\hline
\end{tabular}

The purpose of preparing floating microspheres was to extend the gastric residence time of a drug. The buoyancy test was carried out to investigate the flotability of the prepared microspheres. The microspheres were spread over the surface of a simulated gastric fluid and the fraction of microspheres buoyant and settled down as a function of time was quantitated. The In vitro buoyancy of formulation H1 to HE5 containing polymers HPMC K4M, ethylcellulose and sodium alginate was in range of $74.95 \pm 1.43 \%$ to $95.66 \pm 1.52 \%$ respectively (as shown in table 11 ). H1 was found to have highest in-vitro buoyancy that is $95.66 \pm 1.52$ among all the formulations. The results also revealed a tendency that the larger the particle size, longer the floating time.

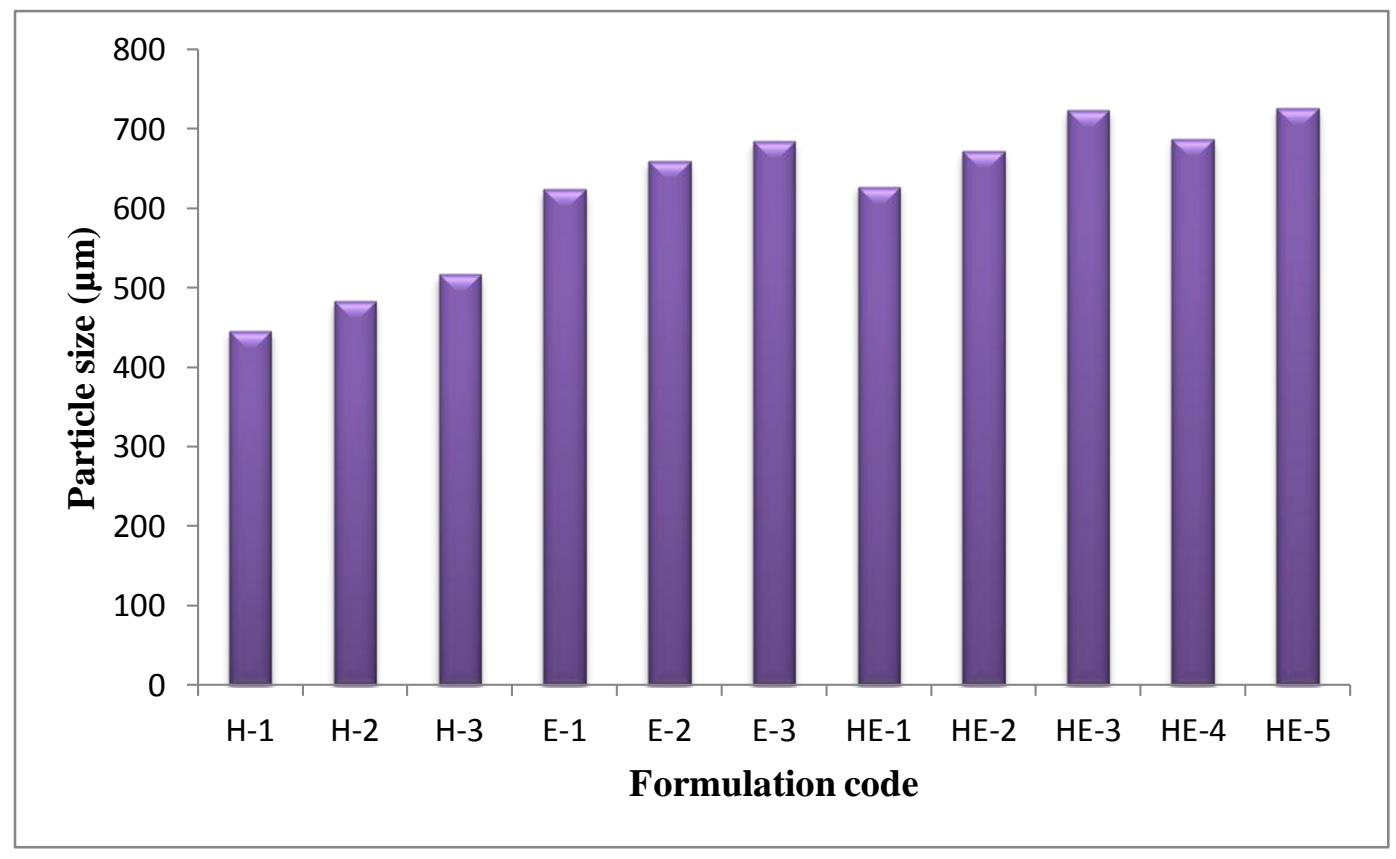

Fig 2:-Comparison of Particle size of floating microspheres of Famotidine $\mathrm{HCl}$ 

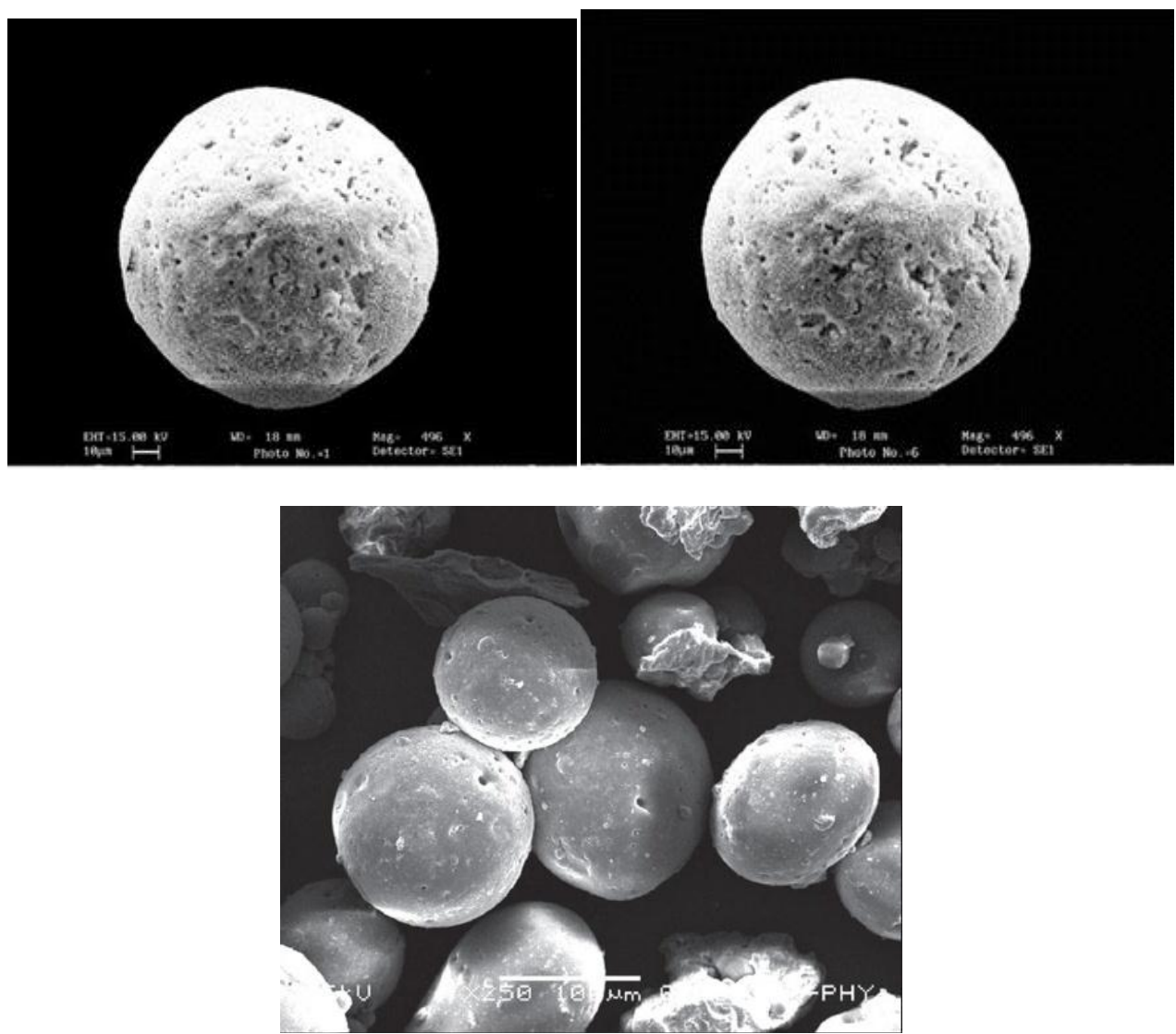

Fig 3:-Scanning electron microphotograph of floating microspheres of Famotidine $\mathrm{HCl} \mathrm{H1}$

Morphology of microspheres was examined by scanning electron microscopy. The view of the microspheres showed a hollow spherical structure with a smooth surface morphology (Fig 29) some of the microspheres showed a dented surface structure but they showed good floating ability on the surface of the medium, indicating intact surface. The outer surface of the microspheres was smooth and dense, while the internal surface was porous. The shell of the microspheres also showed some porous structure (Fig.29). It may be caused by the evaporation of solvent entrapped within the shell of microspheres after forming a smooth and dense skin layer.

Table 3:-In-vitro Drug Release Study of Prepared floating microspheres:

\begin{tabular}{|c|c|c|c|c|c|c|c|c|c|c|c|c|}
\hline \multirow{2}{*}{$\begin{array}{l}\text { Sl. } \\
\text { No }\end{array}$} & \multirow{2}{*}{$\begin{array}{l}\text { Time } \\
\text { (hrs) }\end{array}$} & \multicolumn{11}{|c|}{ Cumulative percent release } \\
\hline & & H-1 & H-2 & H-3 & E-1 & E-2 & E-3 & HE-1 & HE-2 & HE-3 & HE-4 & HE-5 \\
\hline 1 & 0 & 0.00 & 0.00 & 0.00 & 0.00 & 0.00 & 0.00 & 0.00 & 0.00 & 0.00 & 0.00 & 0.00 \\
\hline 2 & 0.5 & $\begin{array}{c}2.41 \\
\pm 0.04\end{array}$ & $\begin{array}{c}2.12 \\
\pm 0.02\end{array}$ & $\begin{array}{c}1.79 \\
\pm 0.03\end{array}$ & $\begin{array}{c}2.15 \\
\pm 0.05\end{array}$ & $\begin{array}{c}1.95 \\
\pm 0.04\end{array}$ & $\begin{array}{c}1.29 \\
\pm 0.03\end{array}$ & $\begin{array}{c}2.35 \\
\pm 0.04\end{array}$ & $\begin{array}{c}2.06 \\
\pm 0.07\end{array}$ & $\begin{array}{c}1.65 \\
\pm 0.02\end{array}$ & $\begin{array}{c}2.46 \\
\pm 0.04\end{array}$ & $\begin{array}{c}1.72 \\
\pm 0.04\end{array}$ \\
\hline 3 & 1 & $\begin{array}{c}5.04 \\
\pm 0.07\end{array}$ & $\begin{array}{c}4.87 \\
\pm 0.06\end{array}$ & $\begin{array}{c}4.22 \\
\pm 0.05\end{array}$ & $\begin{array}{c}4.92 \\
\pm 0.09\end{array}$ & $\begin{array}{c}3.32 \\
\pm 0.03\end{array}$ & $\begin{array}{c}2.82 \\
\pm 0.09\end{array}$ & $\begin{array}{c}4.98 \\
\pm 0.08\end{array}$ & $\begin{array}{c}4.64 \\
\pm 0.06\end{array}$ & $\begin{array}{c}3.69 \\
\pm 0.04\end{array}$ & $\begin{array}{c}4.86 \pm \\
0.02\end{array}$ & $\begin{array}{c}3.06 \\
\pm 0.04\end{array}$ \\
\hline 4 & 1.5 & $\begin{array}{c}8.92 \\
\pm 0.08\end{array}$ & $\begin{array}{c}7.84 \\
\pm 0.09\end{array}$ & $\begin{array}{c}6.94 \\
\pm 0.05\end{array}$ & $\begin{array}{c}7.22 \\
\pm 0.07\end{array}$ & $\begin{array}{c}5.92 \\
\pm 0.09\end{array}$ & $\begin{array}{c}4.36 \\
\pm 0.08\end{array}$ & $\begin{array}{c}7.96 \\
\pm 0.10\end{array}$ & $\begin{array}{c}7.62 \\
\pm 0.07\end{array}$ & $\begin{array}{c}5.84 \\
\pm 0.08\end{array}$ & $\begin{array}{c}7.30 \pm \\
0.09\end{array}$ & $\begin{array}{c}5.76 \\
\pm 0.08\end{array}$ \\
\hline 5 & 2 & $\begin{array}{l}13.80 \\
\pm 0.06\end{array}$ & $\begin{array}{l}12.94 \\
\pm 0.08\end{array}$ & $\begin{array}{l}11.21 \\
\pm 0.07\end{array}$ & $\begin{array}{c}11.24 \\
\pm .12\end{array}$ & $\begin{array}{r}9.81 \\
\pm .12\end{array}$ & $\begin{array}{c}7.95 \\
\pm 0.21\end{array}$ & $\begin{array}{l}13.09 \\
\pm 0.19\end{array}$ & $\begin{array}{c}12.82 \\
\pm .10\end{array}$ & $\begin{array}{c}9.46 \\
\pm 0.10\end{array}$ & $\begin{array}{l}12.69 \\
\pm 0.12\end{array}$ & $\begin{array}{c}8.79 \\
\pm 0.09\end{array}$ \\
\hline 6 & 3 & $\begin{array}{l}19.22 \\
\pm 0.29\end{array}$ & $\begin{array}{l}18.17 \\
\pm 0.12\end{array}$ & $\begin{array}{l}16.11 \\
\pm 0.95\end{array}$ & $\begin{array}{c}15.62 \\
\pm .31\end{array}$ & $\begin{array}{c}12.90 \\
\pm .12\end{array}$ & $\begin{array}{r}11.22 \\
\pm 0.25\end{array}$ & $\begin{array}{l}18.75 \\
\pm 0.21\end{array}$ & $\begin{array}{c}16.95 \\
\pm .13\end{array}$ & $\begin{array}{c}14.28 \\
\pm .11\end{array}$ & $\begin{array}{l}17.62 \\
\pm 0.18\end{array}$ & $\begin{array}{r}11.82 \\
\pm 0.12\end{array}$ \\
\hline 7 & 4 & $\begin{array}{l}23.40 \\
\pm 0.13\end{array}$ & $\begin{array}{l}22.28 \\
\pm 0.09\end{array}$ & $\begin{array}{r}19.36 \\
\pm 0.89\end{array}$ & $\begin{array}{c}19.22 \\
\pm .21\end{array}$ & $\begin{array}{c}17.54 \\
\pm .31\end{array}$ & $\begin{array}{r}15.86 \\
\pm 0.22\end{array}$ & $\begin{array}{l}22.82 \\
\pm 0.25\end{array}$ & $\begin{array}{c}20.68 \\
\pm .26\end{array}$ & $\begin{array}{c}17.84 \\
\pm .09\end{array}$ & $\begin{array}{l}21.45 \\
\pm 0.14\end{array}$ & $\begin{array}{r}16.55 \\
\pm 0.27\end{array}$ \\
\hline 8 & 5 & 32.70 & 28.11 & 24.82 & 24.16 & 22.41 & 20.49 & 29.65 & 27.81 & 22.66 & 28.62 & 21.48 \\
\hline
\end{tabular}




\begin{tabular}{|c|c|c|c|c|c|c|c|c|c|c|c|c|}
\hline & & \pm 0.38 & \pm 0.23 & \pm 0.26 & \pm 0.42 & \pm 0.35 & \pm 0.42 & \pm 0.31 & \pm 0.31 & \pm 0.21 & \pm 0.17 & \pm 0.31 \\
\hline 9 & 6 & 44.12 & 37.27 & 39.12 & 29.69 & 27.38 & 24.36 & 39.76 & 38.22 & 47.24 & 38.72 & 25.32 \\
& & \pm 0.44 & \pm 0.35 & \pm 0.31 & \pm 0.40 & \pm 0.35 & \pm 0.16 & \pm 0.21 & \pm 0.19 & \pm 0.25 & \pm 0.34 & \pm 0.39 \\
\hline 10 & 7 & 56.22 & 45.86 & 42.45 & 35.93 & 32.48 & 29.59 & 48.86 & 46.68 & 38.26 & 47.24 & 28.89 \\
& & \pm 0.15 & \pm 0.26 & \pm 0.28 & \pm 0.39 & \pm 0.45 & \pm 0.43 & \pm 0.35 & \pm 0.56 & \pm 0.25 & \pm 0.37 & \pm 0.42 \\
\hline 11 & 8 & 61.82 & 54.71 & 49.62 & 41.21 & 38.66 & 34.72 & 65.62 & 52.06 & 45.62 & 55.65 & 35.56 \\
& & \pm 0.29 & \pm 0.28 & \pm 0.36 & \pm 0.27 & \pm 0.45 & \pm 0.57 & \pm 0.49 & \pm 0.64 & \pm 0.47 & \pm 0.38 & \pm 0.64 \\
\hline 12 & 9 & 65.94 & 62.32 & 55.77 & 48.96 & 42.27 & 39.82 & 63.46 & 61.42 & 50.85 & 62.45 & 40.36 \\
& & \pm 0.38 & \pm 0.46 & \pm 0.74 & \pm 0.66 & \pm 0.51 & \pm 0.63 & \pm 0.41 & \pm 0.68 & \pm 0.59 & \pm 0.41 & \pm 0.51 \\
\hline 13 & 10 & 67.22 & 64.89 & 58.26 & 53.36 & 47.33 & 45.35 & 65.69 & 64.27 & 54.68 & 65.49 & 46.65 \\
& & \pm 0.49 & \pm 0.12 & \pm 0.16 & \pm 0.14 & \pm 0.12 & \pm 0.15 & \pm 0.12 & \pm 0.13 & \pm 0.11 & \pm 0.12 & \pm 0.14 \\
\hline 14 & 11 & 69.11 & 66.75 & 61.13 & 60.45 & 52.24 & 50.47 & 67.82 & 65.95 & 58.54 & 66.74 & 51.25 \\
& & \pm 0.66 & \pm 0.09 & \pm 0.13 & \pm 0.16 & \pm 0.12 & \pm 0.19 & \pm 0.15 & \pm 0.11 & \pm 0.12 & \pm 0.14 & \pm 0.14 \\
\hline 15 & 12 & 71.21 & 70.55 & 66.78 & 65.36 & 56.26 & 54.56 & 70.56 & 68.37 & 64.65 & 69.92 & 55.82 \\
& & \pm .59 & \pm 0.72 & \pm 0.96 & \pm 0.96 & \pm 0.81 & \pm 0.93 & \pm 0.98 & \pm 0.90 & \pm 0.99 & \pm 0.98 & \pm 0.96 \\
\hline 16 & 24 & 98.84 & 88.22 & 76.28 & 77.82 & 67.29 & 65.25 & 89.64 & 77.02 & 74.82 & 84.54 & 67.32 \\
& & \pm 2.16 & \pm 2.13 & \pm 2.10 & \pm 2.09 & \pm 2.10 & \pm 2.13 & \pm 2.14 & \pm 2.13 & \pm 2.09 & \pm 2.06 & \pm 2.10 \\
\hline
\end{tabular}

The percentage yield of floating microsphere formulation of H1 to HE5 was in range of $81.03 \pm 1.12$ to $97.82 \pm 2.31$. To observe the effect of polymer concentration on the percentage yield of the floating microspheres, formulations were prepared at varying concentration of polymer, and it was observed that the yield of the floating microspheres increased with increasing polymer concentration. The entrapment efficiency of formulation H1 to HE5 containing polymers like HPMC K4M, ethyl-cellulose and sodium alginate was in the range of $83.55 \pm 1.26$ to $98.02 \pm 2.09$ respectively, (as shown in table 11) and from the results it is observed that $\mathrm{H} 1$ had best incorporation efficiency with $98.02 \pm 2.09$. This indicated that decrease in concentration of polymer increased the entrapment efficiency of the drug. The drug entrapment efficiency was found to be good in all formulations

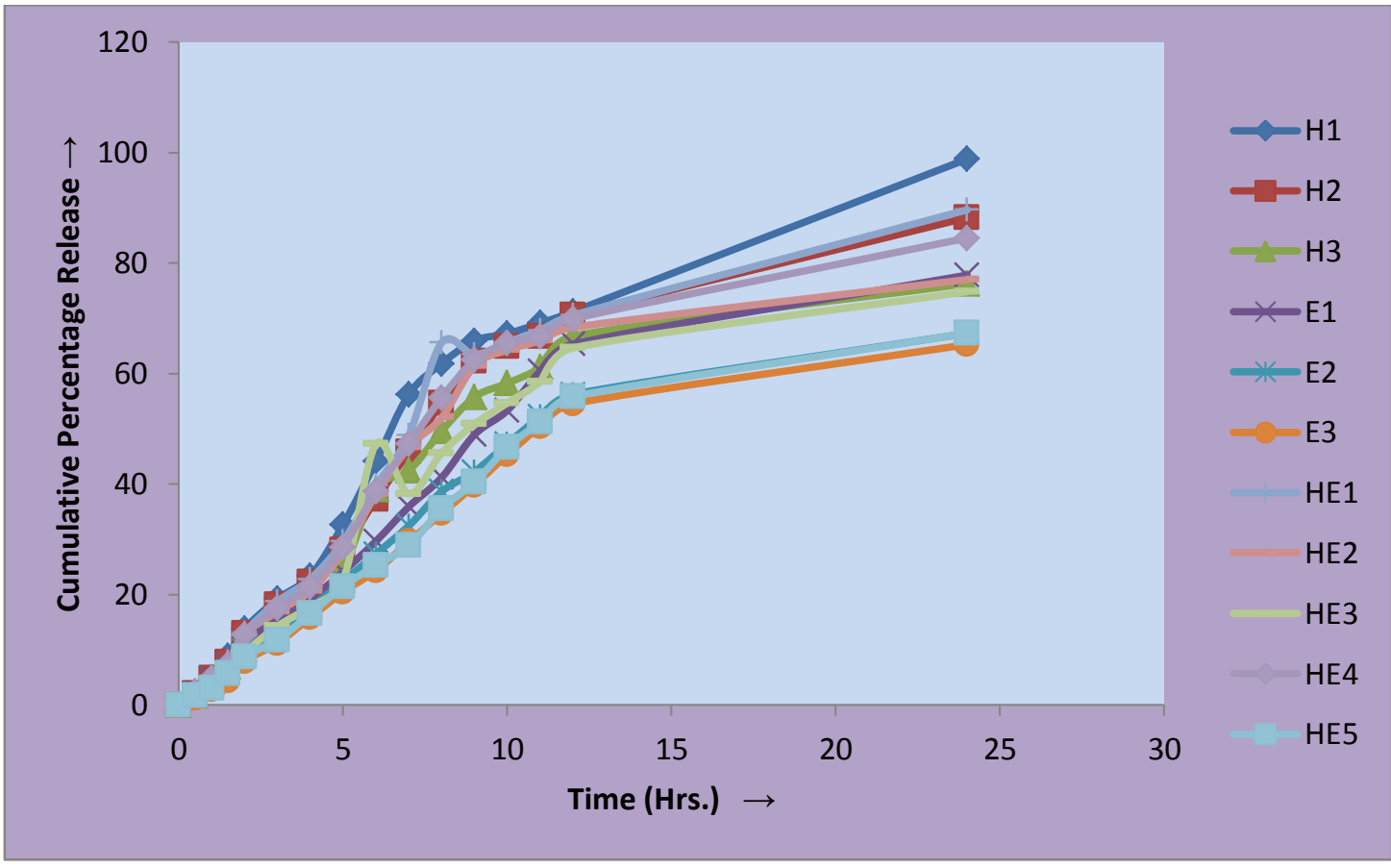

Fig 4:-Comparative in vitro diffusion profiles of Famotidine HCl FDDS according to Cumulative percentage release 


\section{Discussion:-}

Floating drug delivery system have a bulk density less than gastric fluids and thus it remains buoyant in the stomach without affecting gastric emptying rate for a prolonged period of time. However the system is floating on the gastric contents, the drug is released slowly at the desired rate from the system, after complete release of drug the residual system is emptied from stomach. This results in an increased gastric residence time and a better control on the fluctuation in plasma drug concentration time profile. Single unit formulations (floating tablet) are associated with problems such as sticking together or being obstructed in the gastrointestinal tract, which may have a potential danger of producing irritation. On the other hand a floating system made of multiple unit forms (floating microspheres) has relative merits compared to a single unit preparation. Floating microspheres provide a constant and prolonged therapeutic effect which will reduce dosing frequency

\section{In vitro drug release:}

In-vitro drug release studies of all the Famotidine $\mathrm{HCl}$ floating microspheres were performed in $\mathrm{pH} 1.2$ for $24 \mathrm{hrs}$, in dissolution test apparatus, and it was observed that in vitro drug release of formulations H1 to HE5 shows percentage of drug release in the range of $65.25 \pm 2.13$ to $98.84 \pm 2.16$ at end of 24 hrs. Result revealed that again among all the formulation $\mathrm{H} 1 \mathrm{was}$ found to be the best formulation as it release Famotidine $\mathrm{HCl} 98.84 \%$ in a sustained manner with constant fashion over extended period of time (after $24 \mathrm{hrs}$ ). The release did not show any burst effect or lag time, which is indicative of a homogenous drug distribution.

It was observed that as the concentration of HPMC K4M is increased the percent release of Famotidine HCL decreases. The increase in ethyl-cellulose concentration leads to the increased density of polymer matrix into the microspheres which result in an increased diffusional path length. This may decrease the overall drug release from polymer matrix. The smaller microspheres are formed at lower polymer concentration and have larger surface area exposed to dissolution medium, and the $r$ values of Zero order of all the formulations were found to be in the range of 0.801 to 0.889 . Similarly the r-Value of first Order were in between 0.884 to 0.980 , among the all formulations some formulations release the drug by zero order kinetics and some is release by first order kinetics. The results suggest that, the drug was released by mixed order kinetics. To ascertain, the drug release mechanism the in-vitro release data were also subjected to Higuchi's diffusion equation and $(Q=k . t 1 / 2)$ the $r$-values of all the formulations of Higuchi's equations were 0.980. It suggests that the Higuchi diffusion plots of all the formulations were fairly linear and we can conclude that the drug released by Higuchi's diffusion mechanism. The formulations are also treated to Peppa's plots by taking log percent versus log time, the plots are found to be fairly linear and the regression values ( $n$ value) of all formulations ranges from lowest 0.500 to highest 0.657 , which in the range of 0.45 $<\mathrm{n}<0$. 89. This suggests that the drug was released by non-Fickian control (Anomalous diffusion) with swelling. Four types of graphs i.e., cumulative percent drug release, first order, Higuchi diffusion and Peppa's exponential plots of all formulations were shown in figure 31-35.

\section{Conclusion:-}

Floating microspheres of Famotidine HCL can be successfully prepared using HPMC K4M, ethylcellulose and sodium alginate as polymers by ionotropic gelation technique. The percent yield of all floating microspheres formulations was more than $60 \%$ suggesting that the methods used for encapsulation was effective. The optimized multi - unit floating microspheres of Famotidine HCL may prove to be potential candidate for safe and more bioavailable formulation in the management of Gastroesophaegal reflux. Therefore, it may be concluded that the drug loaded floating microsphres are a suitable delivery system for Famotidine HCL and may be used for effective management of Gastroesophaegal reflux.

\section{References:-}

1. Yeole PG, Khan S, Patel VF. floating drug delivery systems: Need and Development. Ind. J. Pharm. Sci. 2005; 67(3): 265-272.

2. Banker GS, Anderson NR. Tablets: The theory and practice of industrial pharmacy. $3^{\text {rd }}$. Bombay : Varghese Pub. House; s2003.

3. Chein YW. Novel Drug Delivery Systems. 2nd ed. New York: Marcel Dekker. Inc.1992.

4. Lee TW, Robinson JR. Remington: The Science and Practice of Pharmacy. 20 ${ }^{\text {th }}$ ed. Pennsylvania: Mack Publishing Company; 2001.

5. Aulton ME. Pharmaceutics: The Science of Dosage Form Design. $2^{\text {nd }}$ ed. Livingstone C. Elsevier science Ltd; 2002. 
6. Welling PG, Dobrinska M.Controlled drug delivery: Fundamentals and applications. 2nd ed. New York: Marcell Dekker Inc; 1987.

7. Brahmankar DM, Jaiswal SB. Biopharmaceutics and Pharmacokinetics a treatise. Reprint of $1^{\text {st }}$ Edn. Delhi : Vallabh Prakashan; 2003.

8. Anurag Sood, Ramesh Panchagnula. Design of controlled release delivery systems using a modified pharmacokinetic approach: a case study for drugs having a short elimination half-life and a narrow therapeutic index. International Journal of Pharmaceutics 2003; 261: 27-41.

9. Vyas SP, Khar RK. Gastro-retentive system In: Controlled Drug Delivery System: Concept \& Advances. $1^{\text {st }}$ edi. New Delhi:Vallabh Prakashan; 2002.

10. Arora S, Ali J, Ahuja A, Khar RK, Baboota S. Floating drug delivery system. A review. AAPS Pharm Sci Tech 2005; 6(3): 372-390.

11. Chawla G, Gupta P, Koradia V, Bansal AK. Gastroretention A means to address regional variability in intestinal drug absorption.Pharmaceutical Technology 2003:50-68.

12. Singh B, Ahuja N. Progress in Controlled and Novel Drug Delivery System. New Delhi: CBS Publishers and Distributors; 2004.

13. Etyan, AK, Eran, L, Michel, F, Hoffman, A. Expandable gastroretentive dosage forms. J. Cont. Rel. 2003; 909: 143-162.

14. Chatterjee CC. Human Physiology, Medical allied Agency, $11^{\text {th }}$ Edition. 2001

15. Aspde TJ, Mason JDT, Jones NS, Lowe J, Skaugrud O, Illum L. Chitosan as a nasal delivery system: The effect of chitosan solutions on in vitro and in vivo mucociliary transport rates in human turbinates and volunteers. $\mathbf{J}$ Pharm Sci 1997; 86: 509-513.

16. Garg S, Sharma S. Gastroretentive drug delivery systems. Business Brief Pharmatech 5 ${ }^{\text {th }}$ edi. 2003: Available at: http://www.touchbriefings.com/cdps/cditem.cfm?NID-17\&CID-5

17. Singh BN, Kwon HK. Floating drug delivery systems: an approach to oral controlled drug delivery via gastric retention. Journal of Controlled Release 2000; 63:235-249.

18. Amnon Hoffmana, David SA, Eran Lb, Sara EA, Eytan KA, Michael FA. Pharmacokinetic and pharmacodynamic aspects of gastroretentive dosage forms. International Journal of Pharmaceutics 2004; 277: $141-153$

19. Bardonnet PL, Faivre V, Pugh WJ, Piffaretti JC, Falson F. Gastroretentive Dosage Forms: Overview and Special case of Helicobacter pylori. Journal of Controlled Release 2006; 111: 1-18

20. AV Mayavanshi, SS Gajjar. Floating drug delivery systems to increase gastric retention of drugs: A Review. Research J. Pharm. and Tech. 2008; 1(4): 345-358.

21. Fix JA, Cargill R, Engle E. Controlled gastric emptying III. Gastric residence time of a non-disintegrating geometric shape in human volunteers. Pharm Res 1993; 10: 1087-1089.

22. Hilton AK, Deasai PB. Invitro and In vivo evaluation of an oral sustained release dosage form of Amoxycillin trihydrate. Int J Pharm 1992; 86:79- 88.

23. Shivkumar HG, Vishakanta GD, PramodKumar TM. Formulation and evaluation of mucoadhesive drug delivery system for some anti-asthmatic drugs. IJPE 2004 Oct-Dec.; 38(4): 22-26

24. Patel A, Ray S, Thakur RS. In vitro evaluation and optimization of controlled release floating delivery system of metformin hydrochloride. DARU 2006; 55: 277-285.

25. S. K. singh, C.H. Borkhataria, Dr.N.R.Seth: Formulation and in-vitro evaluation of lansoprazole micropellets. Int. journal of pharmatech research oct-dec 2009(1);1530-1540

26. Sato Y, Kawashima Y, Takeuchi H, Yamamoto H. in vivo evaluation of riboflavin-containing microballoons for floating controlled drug delivery system in healthy human volunteers. J Control Release 2003; 93(1): 39-47.

27. Jain NK. Controlled and Novel Drug Delivery. 1st ed. New Delhi :CBS Publishers and Distributors; 2002.

28. Swarbrick J, Boylan JC. Encyclopedia of Pharmaceutical Technology. $2^{\text {nd }}$ ed.USA: Marcel Dekker Inc;2002.

29. Stanley Davis. Formulation statergies for absorption windows. DDT 2005;10(4):249-257.

30. Martin A, Swarbrick J, Cammarata A. Physical Pharmacy. 2nd ed. Bombay: Varghese Publishing Company; 1991.

31. Carstensen JT. Pharmaceutics of solids and solids dosage forms. John Wiley and Sons. Newyork, 1976; 136230.

32. Salunke P, Rane B, Bakliwal S, Pawar S. Floating microcarriers of an antidiabetic drug: preparation and its invitro evaluation. J.of Pharm. Sci. and Tech. 2010; 2(6): 230-240.

33. Kumar R, Patil S, Patil MB, Patil SR, Paschapur MS. Isolation and evaluation of disintegrant properties of fenugreek seed mucilage. Int. J. of Pharm. Tech. Oct-Dec. 2009; 1(4): 982-996. 